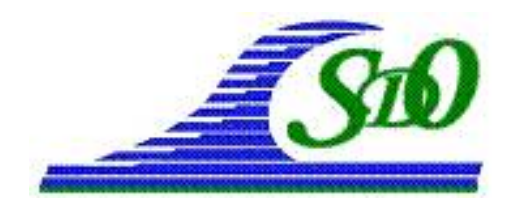
XI ${ }^{\text {èmes }}$ Journées Nationales Génie Côtier - Génie Civil
Les Sables d'Olonne, 22-25 juin 2010

DOI:10.5150/jngcgc.2010.030-G（C) Editions Paralia CFL

disponible en ligne - http://www.paralia.fr - available online

\title{
Outil de gestion des ressources en eau dans la zone côtière : Modélisation hydrodynamique de l'aquifère Plio-Quaternaire de la côte orientale du cap bon au nord est de la Tunisie
}

\author{
Noureddine GAALOUL ${ }^{1}$ \\ 1. Institut National des Recherches en Génie Rural Eaux et Forêts (INRGREF), \\ Rue Hédi Karray B.P.10, 2080 Ariana, Tunisie. \\ gaaloul.noureddine@iresa.agrinet.tn
}

\section{Résumé :}

Face à une demande en eau sans cesse croissante et de ressource en eau rare, caractérisées par une grande variabilité spatiale et temporelle, la gestion intégrée et optimisée de ces ressources à l'échelle régionale s'impose. Cette gestion est indispensable pour subvenir à une demande en eau sans cesse croissante et pour préserver les ressources en tant du point de vue quantité que qualité.

La région du Cap-Bon est localisée au Nord-Est du pays. L'aquifère de la Côte Orientale occupe une superficie d'environ $475 \mathrm{~km}^{2}$. Le climat de la Côte Orientale du Cap-Bon est du type semi-aride à influence méditerranéenne.

La modélisation hydrodynamique de l'aquifère Plio-Quaternaire de la Côte Orientale du Cap-Bon par MODFLOW a permis de comprendre le fonctionnement hydrodynamique de l'aquifère, en estimant les échanges latéraux de la l'aquifère avec la mer Méditerranée et son réseau hydrographique. Ainsi le calage du modèle mathématique en régime permanent sur l'état piézométrique de 1963 a permis d'affiner la distribution spatiale de la perméabilité sur l'ensemble du domaine et de dresser le bilan de l'aquifère en régime permanent. Le calage du modèle en régime transitoire a permis d'affiner la distribution spatiale du coefficient d'emmagasinement de l'aquifère. Le bilan issu de ce calage a mis en évidence des entrées d'eau de mer. Le déstockage enregistré est de l'ordre de 4 $\mathrm{Mm}^{3}$ /an. La recharge artificielle de l'aquifère dans la zone de Diarr El Hojjaj-Menzel Témime avec un débit d'injection de 200 l/s est capable d'inverser le gradient hydraulique et donc de faire reculer le biseau salé dans cette zone.

\section{Mots-clés :}

GIZC - Zones Côtières - Hydrodynamique - Modélisation - Cap Bon - Côte orientale - Tunisie

\section{Communication non présentée}


Thème 2 - Dynamique sédimentaire et transports des particules 
XI ${ }^{\text {èmes }}$ Journées Nationales Génie Côtier - Génie Civil

Les Sables d'Olonne, 22-25 juin 2010 
Thème 2 - Dynamique sédimentaire et transports des particules 
XI $I^{\text {èmes }}$ Journées Nationales Génie Côtier - Génie Civil

Les Sables d'Olonne, 22-25 juin 2010 
Thème 2 - Dynamique sédimentaire et transports des particules 
XI ${ }^{\text {èmes }}$ Journées Nationales Génie Côtier - Génie Civil

Les Sables d'Olonne, 22-25 juin 2010 
Thème 2 - Dynamique sédimentaire et transports des particules 